\title{
EINSTEIN Y POPPER
} Luz María Chapa*

RESUMEN: Pooper afirmaba que lo distintivo de las teorías científicas no es su confirmación, sino el desafío de la experiencia que las someta a falsificación. Einstein proporcionó los elementos para el fabilibismo y Popper los transformó en metodología científica (falsacionismo).

PALABRAS CLAVE: Einstein, Popper, pseudociencia, falibilismo, falsacionismo, actitud crítica.
ABSTRACT: Popper claimed that what distinguished scientific theories was not their confirmation but the challenge they faced when submitted to falsification. Einstein provided the elements for fallibilism while Popper transformed them into a scientific methodology (falsificationism).

KEYWORDS: Einstein, Popper, pseudoscience, fallibilism, falsificationism, critical attitude.
RECEPCIÓN: 16 de febrero de 2010.

ACEPTACIÓN: 7 de diciembre de 2010.
* Departamento Académico de Estudios Generales, ITAM. 
Karl Popper fue uno de los pensadores más influyentes del siglo XX. Llevó a cabo importantes contribuciones -en algunos casos revolucionariasen campos muy variados: desde la filosofía de la ciencia y la teoría del conocimiento, la filosofía de la física y la biología, la lógica, la teoría de la probabilidad, pasando por la filosofía social y política, la filosofía de la historia y la historia de la filosofía, hasta el problema cuerpo-mente, la psicología y la música.

Popper fue un innovador y un crítico en la tradición de Russell, Wittgenstein, Einstein, Tarski y Quine. De hecho, los tres pensadores más admirados por Popper fueron Einstein,

* Reflexiones con motivo del Centésimo aniversario de la publicación de la teoría de la relatividad especial.
Russell y Tarski, y el más aborrecido fue Wittgenstein. ${ }^{1}$ Resulta de particular interés la correspondencia de Popper con Einstein y con Russell, y la que mantuvo con algunos miembros del Círculo de Viena y de otros grupos dentro del movimiento de la filosofía científica, en donde Einstein era considerado uno de los principales representantes de la concepción científica del mundo en el más pleno sentido. Popper reconoció siempre la enorme influencia de Einstein en su pensamiento y llegó incluso a afirmar, al hablar de su filosofía de la ciencia: "lo que he hecho principalmente es hacer explícitos

${ }^{1}$ Cf. K. Popper, “The philosophy of Russell: II. Discussion among Karl Popper, Peter Strawson and Geoffrey Warnock", en B. Magee (ed.), Modern British Philosophy, capítulo 1971, London, Secker \& Warburg, capítulo 7. 
ciertos puntos que estaban implícitos en el trabajo de Einstein". ${ }^{2}$

Muchos autores consideran que ningún otro pensador del siglo pasado ha tenido el nivel de efectividad de Popper como destructor de algunos mitos dominantes de su época, entre los que están las pretensiones de cientificidad del marxismo y del psicoanálisis, y su aguda crítica del positivismo lógico.

\section{La actitud crítica o actitud científica}

Popper consideró que la actitud de Einstein era la clave de la actitud crítica o cientifica que faltaba al marxismo y al psicoanálisis, ${ }^{3}$ y estaba convencido de que la revolución einsteiniana, al negar los conceptos de espacio y tiempo absolutos, removió los cimientos de lo que por tres siglos se consideró intocable: la física clásica newtoniana. Puso de manifiesto el carácter conjetural e hipotético de las teorías científicas, las cuales no necesitan justificación, en contraste con lo que afirmaban los seguidores de Mach y del primer Wittgenstein, como eran los positivistas lógicos del Círculo de Viena.

${ }^{2} \mathrm{~K}$. Popper, "The Influence of Einstein on my View of Science", Radio Broadcast, 23 de febrero de 1966, Popper Archives, Hoover Institute, Stanford, (82.17).

${ }^{3}$ Cf. K. Popper, Unended Quest. An Intellectual Autobiography, 1990, La Salle (Illinois), Open Court, 51-2. Vid. "Science: Conjectures and Refutations" en Conjectures and Refutations, The Growth of Scientific Knowledge, 1963, London, Routledge, 33-65.
Desde 1919, la comparación entre la relatividad general con las doctrinas pseudocientíficas - como el marxismo y el psicoanálisis- le llevaron a la conclusión de que lo que distingue a las mejores teorías científicas no es que sean siempre confirmadas por la experiencia, sino que son siempre desafiadas por la experiencia que las somete al riesgo de la falsificación.

A este respecto, escribía Einstein a su amigo Besso, en 1914: "ya no dudo de la corrección de todo el sistema, aún si la observación del eclipse solar es exitosa o no". Sin embargo estaba encantado cuando, después de siete años de espera, la predicción fue confirmada.

La admiración es otro rasgo de la mentalidad científica que Einstein ejemplificó cabalmente. Estaba persuadido de que "quien no posee el don de maravillarse ni de entusiasmarse más le valdría estar muerto, porque sus ojos están cerrados". Esto le llevó a insistir en la importancia de la curiosidad intelectual: "lo importante es no dejar de hacerse preguntas", ${ }^{4} \mathrm{y}$ de fomentar la curiosidad en la enseñanza para combatir los estragos de una enseñanza basada en manuales: "es prácticamente un milagro que los modernos métodos de enseñanza no hayan eliminado del todo la sagrada curiosidad de la investigación; porque esta delica-

${ }^{4}$ A. Einstein, Conferencia en el King's College, Londres, 1921, en http://www.astrocosmo.cl/b ptiempo/b_p-tiempo-05.03.htm. 
NOTAS

da plantita necesita más que nada, más que la estimulación, su libertad". 5

\section{El carácter conjetural o hipotético de las teorías científicas}

Popper y Einstein hicieron más que nadie por destruir la visión inductivista y justificacionista de la ciencia, sostenida casi universalmente a inicios del siglo veinte: la idea de que el conocimiento científico está construido sobre la base de la observación directa y que lo que lo hace especial es su certeza absoluta:

Desde luego las teorías que consideramos que no son más que conjeturas o hipótesis que no necesitan justificación (al menos no una justificación a través de un "método de inducción", del que nadie ha dado nunca una descripción inteligente). Sin embargo algunas veces podemos dar razones para preferir una de las conjeturas en juego a otras, a la luz de su discusión crítica. Todo esto era claro y altamente coherente, pero muy diferente de lo que decían los positivistas machianos y los wittgensteinianos del Círculo de Viena". 6

Einstein abandonó el positivismo en sus últimos años y confió a Popper que lamentaba el haber apoyado una actitud que ahora consideraba no sólo

${ }^{5}$ A. Einstein, Out of My Later Years, 1995, New York, Carol Publiching Group, p. 34.

${ }^{6}$ K. Popper, Autobiography, op. cit., p. 80. equivocada, sino incluso peligrosa para el futuro desarrollo tanto de la ciencia física como de su filosofía. ${ }^{7}$

Popper y Einstein influyeron particularmente en la progresiva flexibilización de criterio de verificación, sostenido por los positivistas lógicos de dicho grupo. El abandono del realismo por parte de Schlick-líder de dicho grupo-y su reorientación hacia la filosofía de Wittgenstein fue lamentado por Popper y también por Einstein, quien le había considerado uno de los mejores intérpretes filosóficos de la teoría de la relatividad, que acabaron criticando su trabajo como demasiado positivista. ${ }^{8}$ Schlick murió asesinado e 1936, pero los antiguos miembros del Círculo, dispersos por Inglaterra y Estados Unidos principalmente, fueron acusando las críticas. En una conversación con Einstein, Carnap -principal exponente del positivismo lógico- explica que en el movimiento de filosofía científica habían abandonado la visión positivista inicial y superado la pretensión de encontrar una base inamovible para el conocimiento:

Entre otras cosas debido a la influencia del libro Logik der Fors-

${ }^{7}$ Cf. K. Popper, "The Influence of Einstein on my View of Science", Radio Broadcast, 23 de febrero de 1966, Popper Archives, Hoover Institute, Stanford, (82.17).

${ }^{8} \mathrm{Cf}$. F. Stadler, The Vienna Circle. Studies in the Origins, Development, and Influence of Logical Empiricism, 2001, Wien, Springer-Verlag, p. 174. 
chung de Popper, (que) iba en la misma dirección. Algunos de nosotros-especialmente Neurath, Hahn y yo-llegamos a la conclusión de que debíamos procurar un criterio de significado más liberal que la verificabilidad. ${ }^{9}$

Feigl, el mayor impulsor del positivismo lógico en Estados Unidos, estaba de acuerdo con las ventajas de correr el riesgo epistemológico al que invitaba el racionalismo crítico de Popper-conjeturar libre y audazmente, deducir vigorosamente y refutar severamente-,${ }^{10} \mathrm{en}$ virtud de que todo nuestro conocimiento tarde o temprano exige trascender la evidencia:

Sostenemos firmemente (con Einstein y con Popper) que no existe un camino recto que nos conduzca desde los datos de observación a una teoría explicativa. En la construcción de teorías está a la orden del día una gran ingenuidad, con todos los riesgos de "conjeturar mal". Muchos de nosotros estamos de acuerdo con Popper en que $[\ldots]$ si una teoría sobrevive a los retos experimentales, puede 'hasta nuevo aviso', ser considerada como

${ }^{9}$ R. Carnap, "Intellectual Autobiography" en P.A. Schilpp (ed.), The Philosophy of Rudolf Carnap, 1963, La Salle (Illinois), Open court, p. 57.

${ }^{10}$ H. Feigl, "The Power of Positivistic Thinking" en R. Cohen (ed.), Herbert Feigl, Inquiries and Provocations. Selected Writings, 1929-1974, 1981, London, Reidel, pp. 50-1. corroborada [...] mientras no surja una evidencia que la refute. ${ }^{11}$

Popper intentó solucionar lo que le parecían los dos problemas fundamentales de la epistemología: el problema de la inducción o del papel de la experiencia en el conocimiento científico (planteado por Hume), y el problema de la demarcación o del carácter científico de las teorías (planteado por Kant). Aplicado consistentemente, el criterio de significado de Wittgenstein rechaza como carentes de sentido aquellas leyes naturales cuya búsqueda, como decía Einstein, es "la tarea suprema del físico": 12

De acuerdo a Wittgenstein toda proposición con significado ha de ser lógicamente reducible a proposiciones elementales (o atómicas), que caracteriza como descripciones o "pinturas de la realidad" (Cfr. Tractatus, $4.01,4.03$ y 2.221 ) (una caracterización que abarca a todas las proposiciones con sentido). Aquí podemos ver que el criterio de significado de Wittgenstein coincide con el criterio de demarcación de los inductivistas, si reemplazamos sus términos "científico" o "legítimo"

${ }^{11}$ H. Feigl, "The Wiener Kreis in America" en D. Fleming y B. Bailyn (eds.), The Intellectual Migration. Europe and America, 1930-1960, 1969, Cambridge (Massachusetts), Harvard University Press, pp. 76-7.

${ }^{12}$ A. Einstein, The World as I see It, 1934, New York, Covici-Friede, p. 125. 
NOTAS

por "significativo". Y es precisamente a través del problema de la inducción como fracasa este intento de resolver el problema de la demarcación: los positivistas, en su ansia por aniquilar a la metafísica, aniquilan también la ciencia natural. Ya que las leyes científicas tampoco pueden ser reducidas lógicamente a proposiciones elementales de experiencia: no pueden nunca ser aceptadas como proposiciones genuinas o legítimas. ${ }^{13}$

\section{El falibilismo como metodología científica}

Einstein proporcionó los elementos para el falibilismo y Popper los transformó en una metodología científica (falsacionismo). Einstein fue, indudablemente, un falibilista - todo nuestro conocimiento es incierto-, pero no un falsificacionista - la única manera de progresar en el conocimiento es por medio de la crítica, que debe ser tan completa e incesante como sea posible.

Popper fue un ardiente defensor de la existencia de genuinos problemas filosóficos:

Los grandes físicos del Renacimiento -Copérnico, Galileo, Kepler, Gilbert- que volvieron su mirada a Aristóteles y Platón intentaron reemplazar las sustancias o potencias cualitativas de Aristóteles por un método

${ }^{13}$ K. Popper, The Logic of Scientific Discovery, 1997, London, Routledge, p. 36. geométrico de cosmología. En efecto, es lo que significa el Renacimiento (en la ciencia): un renacimiento del método geométrico que fue la base de los trabajos de Euclídes, Aristarco, Arquímedes, Copérnico, Kepler, Galileo, Descartes, Newton, Maxwell y Einstein. Pero ¿puede este desarrollo ser considerado filosófico? ¿no pertenece más bien a la física -a la ciencia factual- y a las matemáticas puras -una rama de la lógica tautológica- como la escuela de Wittgenstein argumentaría? ${ }^{14}$

Sin embargo, Popper se quedó corto debido a su cientismo y a su agnosticismo, al contrario de Einstein, que no dudó en reconocer un mundo ordenado y cognoscible:

existe-afirmaba-un gran mundo exterior, independiente de nosotros, seres humanos, que se presenta ante nosotros como un grande y eterno enigma, accesible al menos en parte a nuestra investigación y a nuestro pensamiento. La contemplación de ese mundo se presenta como una liberación. ${ }^{15}$

Tenía claro que la realidad es más rica que la ciencia:

he aprendido una cosa en mi larga vida: que toda nuestra ciencia,

${ }^{14} \mathrm{~K}$. Popper, Conjectures and Refutations, The Growth of Scientific Knowledge, op. cit., p. 89.

${ }^{15} \mathrm{~A}$. Einstein, Conferencia en el King's College, Londres, 1921, en http://www.astrocosmo. cl/b_p-tiempo/b_p-tiempo-05.03.htm. 
en comparación con la realidad, es primitiva e infantil-y sin embargo es la cosa más preciosa que tenemos. ${ }^{16}$

No dudó en declarar que la humildad era la actitud más acorde frente a la contemplación de la Naturaleza:

lo que veo en la Naturaleza es una magnífica estructura que podemos comprender sólo muy imperfectamente, y que debe llenar a una persona pensante de un sentimiento de humildad. Este es un sentimiento genuinamente religioso que no tiene que ver con el misticismo. ${ }^{17}$

Finalmente, estaba abierto a una inteligencia ordenadora del cosmos:

deseo saber cómo creó Dios este mundo. No estoy interesado en este o aquel fenómeno, en el espectro de este o aquel elemento. Quiero saber Sus pensamientos; el resto son detalles. ${ }^{18}$

${ }^{16}$ A. Einstein, Out of My Later Years, op. cit., p. 23 .

${ }^{17}$ Ibid., p. 24.

${ }^{18}$ A. Einstein, Conferencia en el King's College, Londres, 1921, en http://www.astrocosmo. cl/b_p-tiempo/b_p-tiempo-05.03.htm.
También estaba persuadido de que el hombre encuentra a Dios detrás de cada puerta que la ciencia logra abrir, de manera que, para él, había dos maneras de vivir la vida: una, como si nada fuera un milagro; la otra, como si todo lo fuera.

Con este credo, Einstein proporcionó a la humanidad una visión nueva del universo físico y un modelo de lo que una persona consciente debe alcanzar; pero, sobre todo, dejó clara la centralidad del ser humano sobre el Estado y la ciencia:

El Estado existe para el hombre y no el hombre para el Estado. Lo mismo puede decirse de la ciencia. Estas son viejas frases, acuñadas por gente que vio en la individualidad humana el valor humano más alto. Dudaría en repetirlas, si no fuera por el peligro, siempre recurrente, de que sean olvidadas, especialmente en estos días de organización y estereotipos. ${ }^{19}$ p. 128.

${ }^{19}$ A. Einstein, Out of My Later Years, op. cit., 
CITAM Derechos Reservados.

La reproducción total o parcial de este artículo se podrá hacer si el ITAM otorga la autorización previamente por escrito. 